\title{
Ultrasonic Welding of Magnesium- Titanium Dissimilar Metals: A Study on Thermo-mechanical Analyses of Welding Process by Experimentation and Finite Element Method
}

\author{
Dewang Zhao ${ }^{1}$, Daxin Ren ${ }^{2 *}$, Kunmin Zhao ${ }^{2,3^{*}}$, Pan Sun ${ }^{4}$, Xinglin Guo ${ }^{5}$ and Liming Liu ${ }^{1}$
}

\begin{abstract}
Ultrasonic welding is an effective ways to achieve a non-reactive/immiscible heterogeneous metal connection, such as the connection of magnesium alloy and titanium alloy. But the thermal mechanism of magnesium alloy/titanium alloy ultrasonic welding has not been defined clearly. In this paper, the experimental and the finite element analysis were adopted to study the thermal mechanism during welding. Through the test, the temperature variation law during the welding process is obtained, and the accuracy of the finite element model is verified. The microscopic analysis indicates that at the welding time of $0.5 \mathrm{~s}$, the magnesium alloy in the center of the solder joint is partially melted and generates the liquid phase. Through the finite element analysis, the friction coefficient of the magnesium-titanium ultrasonic welding interface can be considered as an average constant value of 0.28 . The maximum temperature at the interface can exceed $600{ }^{\circ} \mathrm{C}$ to reach the melting point temperature of the magnesium alloy. The plastic deformation begins after $0.35 \mathrm{~s}$ and occurs at the magnesium side at the center of the interface.
\end{abstract}

Keywords: Ultrasonic welding, Magnesium alloys, Titanium alloys, Thermo-mechanical analyses, Finite element analysis

\section{Introduction}

Ultrasonic metal welding is a special method of connecting the similar metal or dissimilar metals by using the mechanical vibration energy of the ultrasonic frequency. Under static pressure, it converts the elastic vibration energy into the frictional work, deformation energy and limited temperature rise between workpiece interfaces, to instantly activate the atoms in the welding area of the work-piece and to enable mutual penetration of the molecules at the interface of the two phases, ultimately achieving the solid connection of the weldment [1]. The ultrasonic welding has been

\footnotetext{
*Correspondence: rendx@dlut.edu.cn; kmzhao@dlut.edu.cn

${ }^{2}$ School of Automotive Engineering, Dalian University of Technology,

Dalian 116024, China

Full list of author information is available at the end of the article
}

widely used in many applications, such as tube sealing and wire joining [2-4]. According to the previous literatures can be seen that, the mechanism of ultrasonic welding of similar and dissimilar metals have been explored from the perspectives of microstructure analysis, mechanical property analysis, temperature field distribution, and stress distribution [5-10]. Most research in the area of USW have worked on the microstructure and the tensile properties of the ultrasonic spot welded joints [11-17]. To date, the ultrasonic welding mechanism has not been defined clearly. The reason is that the welding process is extremely short, and many important mechanical laws, such as flow trend of material, law of plastic deformation, and distribution of temperature field, cannot be obtained by existing tests $[18,19]$. Therefore, numerical simulation has become an important means to investigate 
ultrasonic welding mechanism. Chen Kunkun conducted the thermal-mechanical analysis to explore the effect of ultrasonic energy on the welding process quantitatively [20]. The conclusion is that acoustic softennign effect increases structural deformation significantly, which is beneficial for joint formation. Meanwhile, heat generation from both frictional work and plastic deformation is slightly influenced by acoustic softennign effect. Cai et al. [21] used both Abaqus/ Standard and Abaqus/Explicit to simulate the coupled mechanical-thermal phenomena. The results show that the combination model (Standard/Explicit) can predict the energy and temperature distribution associated with the ultrasonic welding process, as well as distortion. Kim et al. [22] present a finite element analysis model of ultrasonic spot welding to simulate the welding process of Aluminum alloy. The influence of heat, generated by friction and the accompanying large plastic deformation have been observed by the model. De Vries [23] and Elangovan et al. [24] computed friction heat and plastic deformation heat by the heat production formula, then apply heat to the finite element model as boundary conditions. Temperature distribution and their influences on the workpieces, sonotrode and anvil were analyzed.

According to previous literatures can be seen that lots of researches on simulated welding process of softhard materials, such as aluminum-copper, aluminumsteel, and magnesium-steel. However, the simulated welding process of magnesium-titanium dissimilar metals is rarely reported. There are many difficulties in joining dissimilar $\mathrm{Mg} / \mathrm{Ti}$-based alloys. Severe differences between the base metals exist in terms of physical, chemical, and metallurgy properties. In previous studies [12], ultrasonic welding was carried out on magnesium-titanium dissimilar alloys to investigate the influences of welding parameters on joint strength. The artificial neural network optimized by Genetic Algorithm was used to establish an analytical model. On the basis of the continuation of the results, this study resumes work on the ultrasonic welding of magnesium-titanium. Through the experimental study, the temperature variation law during welding and the microscopic phenomenon of the joint cross section are obtained. Finite element model is used to establish the thermal analysis model of magnesium-titanium ultrasonic welding. In comparison with those of the temperature test and the cross-section micro-analysis of the joint, the accuracy of the model is verified, the average friction coefficient during welding is determined, and the variation law of temperature and plastic strain fields during welding is obtained through finite element model analysis.

\section{Experimentation}

In this study, $1.0 \mathrm{~mm}$ thick AZ31 magnesium alloy sheet and $1.0 \mathrm{~mm}$ thick Ti6Al4V titanium alloy sheet were selected. The specimens are $100 \mathrm{~mm}$ long and $25 \mathrm{~mm}$ wide. Sandpaper was used to polish the surfaces of the specimens before welding. The welding of a $10 \times 10 \mathrm{~mm}^{2}$ tip area is conducted under a clamping pressure of $0.3 \mathrm{MPa}$, a power of $2500 \mathrm{~W}$, a frequency of $20 \mathrm{kHz}$, an amplitude of $20 \mu \mathrm{m}$, and welding time ranging from $0.3 \mathrm{~s}$ to $1.3 \mathrm{~s}(0.3,0.5,0.8,1.0,1.3)$.

In ultrasonic welding experiment, the method of measuring temperature usually uses infrared camera and thermocouple [20-24]. The advantages of infrared camera are convenient and fast. But it can only measure surface temperature changes, not internal temperature changes. Thermocouples enable real-time measurement of internal temperature changes. However, when ultrasonic welding on soft materials, the welding process is prone to large deformation of the material. And that lead to failure of the thermocouple. In this experiment, titanium alloy has higher hardness and is not easily deformed during welding. Therefore, thermocouples are used to obtain more accurate temperature changes in welding process. The schematic setup for measuring interfacial temperatures is shown in Figure 1. A hole with a diameter of $0.5 \mathrm{~mm}$ is drilled from the side into the specimen of Ti6Al4V as close to the top surface as possible without penetrating it. A thermocouple of $0.5 \mathrm{~mm}$ in diameter was inserted into the hole. The interfacial surfaces of the to-be-welded specimens were rubbed using a sandpaper. In this manner, the temperature at $0.2 \mathrm{~mm}$ below the weld interface i.e., at the center of the thermocouple, could be measured. The actual interfacial temperatures should be higher than the measurement. The microstructures and fracture surfaces of the joints were observed using an optical microscope (OM) and a scanning electron microscope (SEM) equipped.

\section{Material Model}

The AZ31 magnesium alloy and Ti6Al4V titanium alloy selected in this experiment are common commercial materials, and numerous scholars have studied their mechanical and thermophysical parameters [25-29], as shown in Table 1.

Ultrasonic welding, under the synergistic effect of high-frequency vibration and vertical pressure, generates a large amount of heat rapidly, and heat affects the stress distribution and deformation of materials in the generation and conduction. This process is a typical thermo mechanical coupling. Materials produce a wide range of temperature variation and plastic deformation. Therefore, the constitutive model of the materials needs to consider these two points. In this study, the JC model [30] 


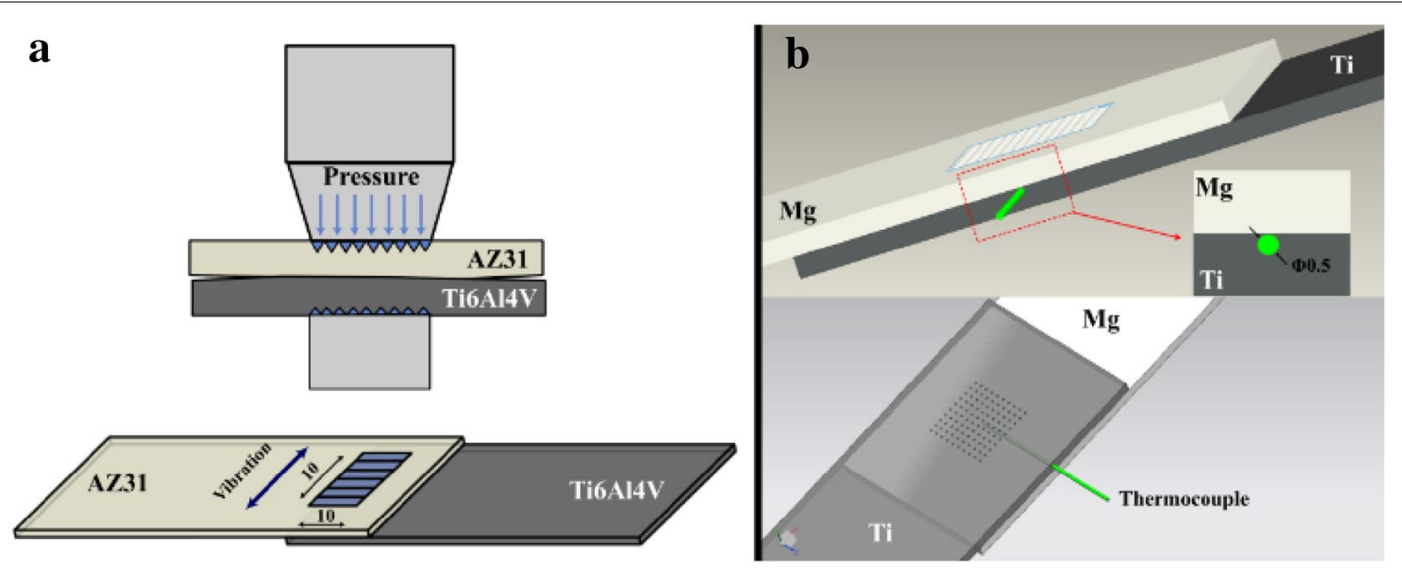

Figure 1 a Mg/Ti ultrasonic welding; $\boldsymbol{b}$ interfacial temperature testing

Table 1 The mechanical and thermophysical parameters of materials

\begin{tabular}{|c|c|c|c|c|c|c|}
\hline & $\begin{array}{l}\text { Conductivity (W/ } \\
(\mathrm{m} \cdot \mathrm{K}))\end{array}$ & $\begin{array}{l}\text { Expansion coefficient } \\
\left(/^{\circ}\right)\end{array}$ & $\begin{array}{l}\text { Heat capacity } \\
\left(\times 10^{6} \mathrm{~J} /\right. \\
\left.\left(\mathrm{m}^{3} \cdot \mathrm{K}\right)\right)\end{array}$ & $\begin{array}{l}\text { Young's modulus } \\
\text { (GPa) }\end{array}$ & Poisson's ratio & Density $\left(\mathrm{kg} / \mathrm{m}^{3}\right)$ \\
\hline AZ31 magnesium & $\begin{array}{l}79\left(20^{\circ} \mathrm{C}\right) \\
92\left(149^{\circ} \mathrm{C}\right) \\
98\left(204^{\circ} \mathrm{C}\right) \\
102\left(260^{\circ} \mathrm{C}\right) \\
105\left(316^{\circ} \mathrm{C}\right) \\
110\left(371^{\circ} \mathrm{C}\right) \\
113\left(627^{\circ} \mathrm{C}\right)\end{array}$ & $\begin{array}{l}2.5 \times 10^{-5}\left(25^{\circ} \mathrm{C}\right) \\
2.7 \times 10^{-5}\left(100^{\circ} \mathrm{C}\right) \\
2.9 \times 10^{-5}\left(200^{\circ} \mathrm{C}\right) \\
3.2 \times 10^{-5}\left(300^{\circ} \mathrm{C}\right)\end{array}$ & $\begin{array}{l}1.02\left(20^{\circ} \mathrm{C}\right) \\
1.34\left(426^{\circ} \mathrm{C}\right)\end{array}$ & $\begin{array}{l}45\left(20^{\circ} \mathrm{C}\right) \\
43.7\left(93^{\circ} \mathrm{C}\right) \\
41.3\left(149^{\circ} \mathrm{C}\right) \\
35.2\left(204^{\circ} \mathrm{C}\right) \\
29.4\left(260^{\circ} \mathrm{C}\right) \\
23.3\left(352^{\circ} \mathrm{C}\right)\end{array}$ & 0.27 & 1740 \\
\hline Ti6Al4V titanium & $\begin{array}{l}6.80\left(20^{\circ} \mathrm{C}\right) \\
7.93\left(100{ }^{\circ} \mathrm{C}\right) \\
8.79\left(200^{\circ} \mathrm{C}\right) \\
10.47\left(300^{\circ} \mathrm{C}\right) \\
12.56\left(400^{\circ} \mathrm{C}\right) \\
14.24\left(500^{\circ} \mathrm{C}\right) \\
15.91\left(600{ }^{\circ} \mathrm{C}\right) \\
17.20\left(800^{\circ} \mathrm{C}\right)\end{array}$ & $\begin{array}{l}9.1 \times 10^{-6}\left(100^{\circ} \mathrm{C}\right) \\
9.2 \times 10^{-6}\left(200^{\circ} \mathrm{C}\right) \\
9.3 \times 10^{-6}\left(300^{\circ} \mathrm{C}\right) \\
9.5 \times 10^{-6}\left(400^{\circ} \mathrm{C}\right) \\
9.7 \times 10^{-6}\left(500^{\circ} \mathrm{C}\right) \\
1.0 \times 10^{-5}\left(600^{\circ} \mathrm{C}\right)\end{array}$ & $\begin{array}{l}2.35\left(20^{\circ} \mathrm{C}\right) \\
2.52\left(200^{\circ} \mathrm{C}\right) \\
2.76\left(400^{\circ} \mathrm{C}\right) \\
3.50\left(600{ }^{\circ} \mathrm{C}\right) \\
3.90\left(800^{\circ} \mathrm{C}\right)\end{array}$ & $\begin{array}{l}114\left(20^{\circ} \mathrm{C}\right) \\
110\left(100^{\circ} \mathrm{C}\right) \\
104\left(200^{\circ} \mathrm{C}\right) \\
98\left(300^{\circ} \mathrm{C}\right) \\
92\left(400^{\circ} \mathrm{C}\right) \\
84\left(500^{\circ} \mathrm{C}\right) \\
74\left(600^{\circ} \mathrm{C}\right)\end{array}$ & 0.34 & 4440 \\
\hline
\end{tabular}

is selected to simulate the constitutive relation of materials. JC dynamic constitutive model describes flow stress as the product form of three functions, namely, strain hardening, strain rate reinforcement, and thermal softening. That is, this model possesses temperature variation and high strain rate. Therefore, the JC model is applicable to this study. The specific forms of the JC model are as follows:

$$
\sigma_{\mathrm{eq}}=\left[A+B\left(\bar{\varepsilon}_{e q}\right)^{n}\right]\left[1+C \ln \left(1+\dot{\varepsilon}_{e q}{ }^{*}\right)\right]\left(1-T^{m}\right),
$$

where $\sigma_{\text {eq }}(\mathrm{MPa})$ is equivalent stress; $\bar{\varepsilon}_{e q}$ is the equivalent plastic strain; $\dot{\varepsilon}_{e q}{ }^{*}$ is the dimensionless plastic strain rate, $\dot{\varepsilon}_{e q}{ }^{*}=\dot{\varepsilon}_{e q} / \dot{\varepsilon}_{0}$, in which $\dot{\varepsilon}_{e q}$ is strain rate in the test and $\dot{\varepsilon}_{0}$ is reference strain rate; $A, B, C, n$ and $m$ are the material parameters measured at or below the reference temperature; $T$ is the non-dimensional temperature defined as:

$$
T \equiv \begin{cases}0, & \text { for } t<t_{r} \\ \left(t-t_{r}\right) /\left(t_{m}-t_{r}\right), & \text { for } t_{r} \leq t \leq t_{m} \\ 1, & \text { for } t>t_{m}\end{cases}
$$

where $t$ is the test temperature, $t_{m}$ is the melting temperature of metals, and $t_{r}$ is the reference temperature defined as the one at or below which there is no temperature dependence on the expression of yield stress. In this study, the reference temperature is set as room temperature, namely $20^{\circ} \mathrm{C}$. The function $T$ as well as constants $A$ (MPa), $B(\mathrm{MPa}), C, n$, and $m$ are determined by related literatures [25-29] as follows (Table 2).

\section{Finite Element Model}

The ultrasonic welding process is simulated by a thermal-mechanical coupling FE model. The model incorporated with commercial software Abaqus 6.16. C3D8RT element is picked to model the work-pieces 
Table 2 Parameters in Johnson-Cook material model

\begin{tabular}{lllllll}
\hline & $\boldsymbol{t}_{\boldsymbol{m}}\left({ }^{\circ} \mathbf{C}\right)$ & $\boldsymbol{A}(\mathrm{MPa})$ & $\boldsymbol{B}(\mathrm{MPa})$ & $\boldsymbol{C}$ & $\boldsymbol{n}$ & $\boldsymbol{m}$ \\
\hline AZ31 magnesium & 641 & 192 & 218.3 & 0.092 & 0.37 & 0.95 \\
Ti6Al4V titanium & 1600 & 870 & 990 & 0.008 & 1.01 & 1.4 \\
\hline
\end{tabular}

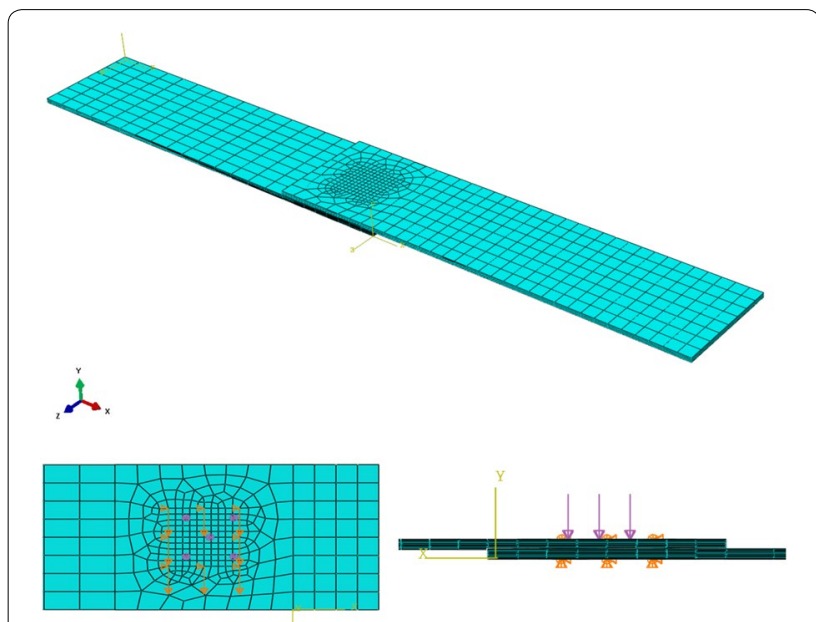

Figure 2 The schematic of FEM

in thermal-mechanical coupled analysis. 'C3D8RT' is 8 node trilinear displacement and temperature element, with reduced integration point and hourglass control. ' $C$ ' stands for continuum, ' 3 ' for trilinear, ' $D$ ' for displacement, ' $\mathrm{R}$ ' for reduced and ' $\mathrm{T}$ ' for temperature. This element type is suitable for thermal-mechanical coupling analysis works, which is the situation of USW. The numerical simulation in this study uses the dynamic and explicit algorithms, and abundant computing resources and long welding time are required to further improve calculation efficiency. This simulation simplifies the sonotrode and fixes all degrees of freedom for the unit at the solder joint corresponding to base plate. Welding is divided into two steps; the first step is directly applying a vertical pressure to the surface unit of the solder joint, and the second step is inducing the surface unit of the solder joint to perform periodic vibration of the ultrasonic frequency to simulate welding (Figure 2). The effect of this simplification is that during actual welding, the surface of the solder joint exhibits plastic deformation, which is consistent with the sonotrode indentation, due to the presence of the sonotrode, and the sonotrode conducts a portion of the heat. However, the focus of this study is on the thermal process and plastic deformation between the contact interfaces, which does not considerably influence the evolution of the interface. Therefore, this simplification is reasonable. The size of FE model is consistent with experiment, as shown in Figure 2. Grids are denser at the welding concentrating area to reduce hour-glassing effect and improve computation accuracy. Specifically, the element size is approximately $0.1 \mathrm{~mm}$ along the thickness direction to accurately get the temperature changes.

Several heat sources, including friction heat produced at the welding interface, heat produced by plastic deformation at the welding interface, and heat produced by plastic indentation on the contact surface between the welding head and the material, exist in ultrasonic welding. Among these, the most important heat source is the friction heat produced at the welding interface. This heat source follows the Coulomb friction model. In $\left|\tau_{\text {fric }}\right|=\mu \cdot p$, a relative sliding is observed at the interface; in $\left|\tau_{\text {fric }}\right| \leq \mu \cdot p$, the interface is relatively static. When the interfaces slip, the interface friction begins. The heat equation is expressed as follows:

$$
q_{f}=\eta \cdot \mu \cdot v,
$$

where $\eta$ is the fraction of frictional heat dissipation, $\mu$ is the coefficient of friction and $v$ is speed of the slipping motion.

Unlike friction heat production, although the heat produced by plastic deformation at the interface is small, it cannot be ignored. The vertical pressure in the ultrasonic welding process does not usually cause the plastic deformation of the interface. However, the modulus of elasticity of materials is reduced with the continuous increase of the welding temperature. In addition to the acoustic softening of materials caused by excess frequency vibration, a large amount of plastic deformation is generated at the welding interface. The heat equation is expressed as follows:

$$
q_{p}=\eta \sigma \dot{\varepsilon}^{p l}
$$

where $\eta$ is the fraction of heat dissipation due to plastic strain which ranges between 0 and $1 . \sigma$ is the effective stress and $\dot{\varepsilon}^{p l}$ is the plastic strain rate.

The transient heat transfer governing equation for ultrasonic welding is as follows [18]:

$$
\rho_{p} c_{p} \frac{\partial T}{\partial t}=\frac{\partial}{\partial x}\left(k_{x} \frac{\partial T}{\partial t}\right)+\frac{\partial}{\partial y}\left(k_{y} \frac{\partial T}{\partial t}\right)+\frac{\partial}{\partial z}\left(k_{z} \frac{\partial T}{\partial t}\right)+Q .
$$


where $\rho_{p}$ is the material density. $c_{p}$ is the material specific heat. $k_{x}$ is the heat conductivities in $x$ direction. $k_{y}$ is the heat conductivities in $y$ direction. $k_{z}$ is the heat conductivities in $z$ direction. $T$ is temperature. $Q$ is the amount of heat generation.

In the kinetic analysis, the mechanical response of the material is controlled by the differential equation of motion. The finite element format is:

$$
\begin{aligned}
& \rho \ddot{u}+c \dot{u}+k u=f, \\
& M \ddot{u}+C \dot{u}+K \dot{u}=F,
\end{aligned}
$$

where $\rho$ is the material mass. $c$ is the damping coefficient. $k$ is the stiffness coefficient. $f$ is the body force. $M$ is the structural mass matrix. $C$ is the structural damping matrix. $K$ is the structural stiffness matrix. $F$ is the vector of the external applied load. $\ddot{u}$ is the nodal accelerations. $\dot{u}$ is the nodal velocity. $u$ is the nodal displacement.

In Abaqus/Explicit algorithm, the temperature response can be controlled by thermal coupling diffusion equation:

$$
Q=C \dot{T}+\Lambda T .
$$

Forward difference integration for temperature can get the following formula:

$$
T_{(i+1)}=T_{(i)}+\Delta t_{(i+1)} C^{-1}(Q-\Lambda T),
$$

where $C$ is the lumped capacitance matrix. $\Lambda$ is the heat transfer matrix. $Q$ is a vector characterizing heat source. $T$ is the temperature at node. $\dot{T}$ is the temperature rate vector. $i$ is the increment number in a dynamic explicit step.

The control formula of the welding process including frequency of ultrasonic vibration and amplitude of sonotrode vibration as follows:

$$
U=U_{\max } \sin (2 \pi f \cdot t),
$$

where $U_{\max }$ is the amplitude of vibration $(20 \mu \mathrm{m}), f$ is vibration frequency $(20 \mathrm{kHz})$ and $t$ is welding time. The product of welding point pressure and welding point area is equal to the product of cylinder pressure and sectionarea. Therefore, the welding point pressure is $40 \mathrm{MPa}$ as the cylinder pressure is $0.3 \mathrm{MPa}$.

\section{Results and Discussions}

\subsection{Experiment Analysis}

Figure 3(a) shows a temperature history diagram at the interface near the center of the solder joint at different soldering times of 300, 500, 800, 1000, and $1300 \mathrm{~ms}$. The maximum temperature at each welding time is at the end

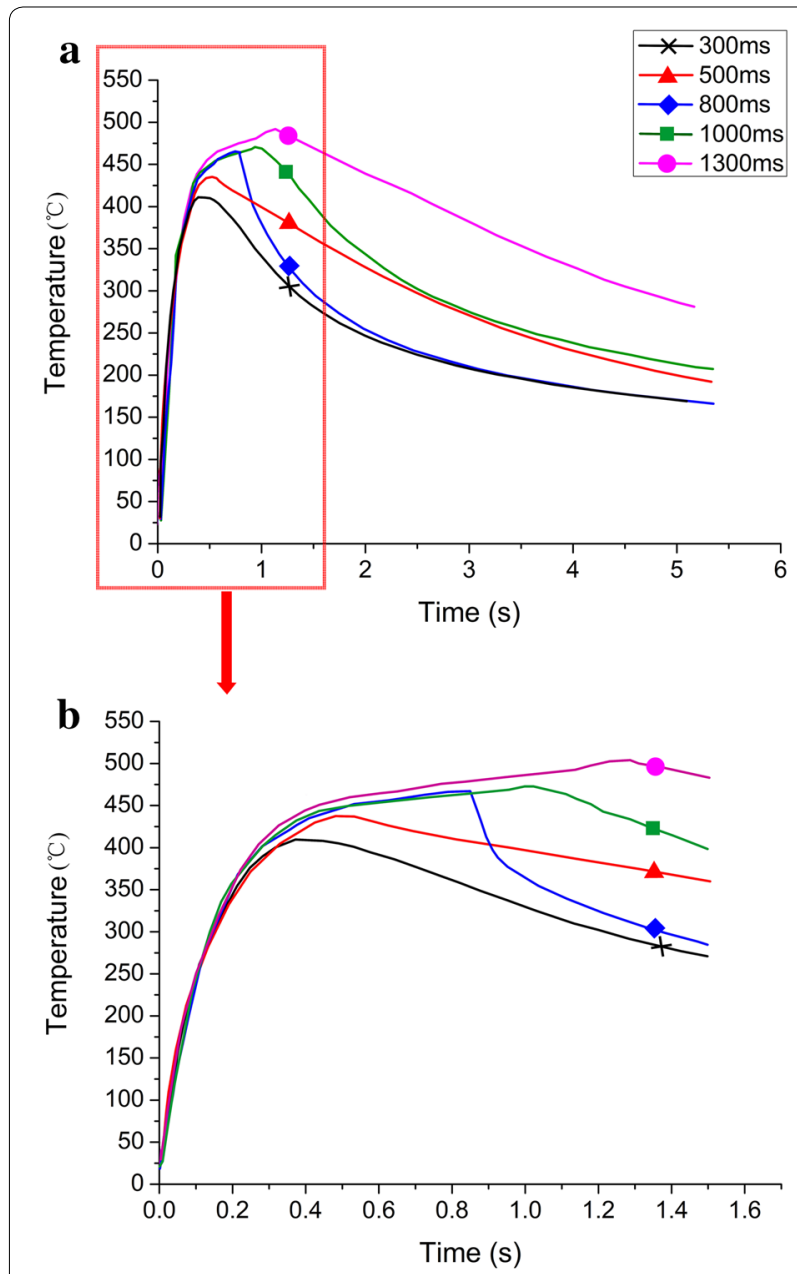

Figure 3 Measured temperatures inside the titanium alloy at $0.2 \mathrm{~mm}$ below the weld interface

of welding (a slight delay occurs due to the delay of heat conduction). The maximum temperature levels at 300 , 500,1000 , and $1300 \mathrm{~ms}$ are $404.3^{\circ} \mathrm{C}, 444.2{ }^{\circ} \mathrm{C}, 472.6^{\circ} \mathrm{C}$, and $504.6{ }^{\circ} \mathrm{C}$, respectively.

For further observing the trend of temperature change, the time history map is enlarged and the history map of the first $1.5 \mathrm{~s}$ is observed, as shown in Figure 3(b). From the figure, the slope of the curve is large before $0.4 \mathrm{~s}$ of welding time, which indicates rapid temperature increase; this increase is the main temperature increase phase of the magnesium-titanium ultrasonic welding. According to the following finite element analysis, the amount of plastic deformation of the material is small at this stage, and the heat generation caused by plastic deformation is minimal; thus, the main source of heat generation at this stage is the frictional heat generation between interfaces. Notably, the slope of the curve before $0.4 \mathrm{~s}$ does considerably change and approaches linearity (the slope of the 
curve begins to decrease only at approximately $0.4 \mathrm{~s}$ ). This result indicates that the friction coefficient does not markedly change during the main temperature increase phase of magnesium-titanium ultrasonic welding. Moreover, the friction coefficient can be considered an average constant value despite dynamically changing. When the welding time approaches $0.4 \mathrm{~s}$ and welding temperature is approximately $430{ }^{\circ} \mathrm{C}$, the slope of the temperature curve begins to decrease sharply. This result indicates that at the beginning, the temperature increase begins gradually and exhibits a steady trend because of the large heat generated by the previous friction after $0.4 \mathrm{~s}$. Although the melting temperature of the magnesium alloy is not reached at this time, the material softens under the action of high temperature and ultrasonic acoustics. When the material softens, the frictional heat generation rate is considerably reduced, and increased temperature is mainly caused by plastic deformation heat generation. In comparison, previous scholars' research shows that despite heat generation and plastic deformation being the main source of heat during ultrasonic welding, heat generation is the main source of heat, whereas plastic deformation produces less heat; thus, a slow or even constant tendency for temperature growth exists.

\subsection{Determination of Friction Coefficient and Temperature Validation}

Friction and wear play an important role during the sliding of two surfaces under cyclic loading. In the field of friction and wear, the coefficient of friction is an important part. Siddiq et al. [31] proposed a friction law which comprises of static and kinematic friction components. Results suggest that, in real experiments, friction work only breaks up the oxide layer at the weld interface and disperse it along and near the interface. Gao and Doumanidis [32] proposed a time dependent friction coefficient by calculation method and finite element method. The results show that the friction coefficient increases almost linearly until a certain time, then remains unchanged, and then begins to decrease over time. Huang et al. [33] investigates the relationships between temperature rise during ultrasonic forming and changes in the friction coefficient. The finite element analysis model used a constant coefficient of friction based on Coulombs friction model. To simulate the experimental behavior, the friction coefficient was reduced when the ultrasonic vibration is applied on the workpieces. Previous studies have established increased friction coefficient variation equations for the slip magnitude, contact pressure, and number of cycles and temperature of the material during ultrasonic welding. In the experimental analysis of the present work, the temperature increase and stationary phases during welding approach a linear trend, the friction coefficient can be considered constant according to the frictional heat generation Eq. (8). This study aims to use the finite element model in adjusting the friction coefficient to match the simulation results with the experimental results, thereby obtaining the friction coefficient of magnesium-titanium ultrasonic welding. The accuracy of FEM is also verified. The test results show that at the temperature increase phase from the beginning of welding to nearly $0.4 \mathrm{~s}$, the welding temperature is approximately $430{ }^{\circ} \mathrm{C}$; after $0.4 \mathrm{~s}$, the stationary phase is reached, and the temperature measurement point is the center position of the solder joint, which is $0.2 \mathrm{~mm}$ from the interface. The test is consistent, and the temperature history curve of the finite element model analysis results also selects the same position. In keeping with the test, the temperature history curve of the numerical model analysis results selects the same position. The friction coefficient by trial and error is highly challenging to determine because the inherent characteristics of the dynamic and explicit algorithms entail short time and few steps, whereas welding time is extended in this study, and calculation of each value requires long time. Finally, the friction coefficient value is 0.28 . Figure 4 shows the comparison between the test and the FEM temperature history. The temperature verification indicates that the simulation and test results agree well, and the maximum error does not exceed $25^{\circ} \mathrm{C}$.

Figure 5(a) shows the joint cross-section of the magnesium-titanium heterogeneous metal at $500 \mathrm{~ms}$. Figure $5(\mathrm{~b})-(\mathrm{d})$ show the interface micro-morphology of the local portion of the center of the solder joint, the edge of the solder joint, and the unwelded portion (the red square in Figure 5(a), respectively. A strip-shaped grain refinement area is found at the local interface of the center of the solder joint (Figure 5(a)), and the enlarged structure

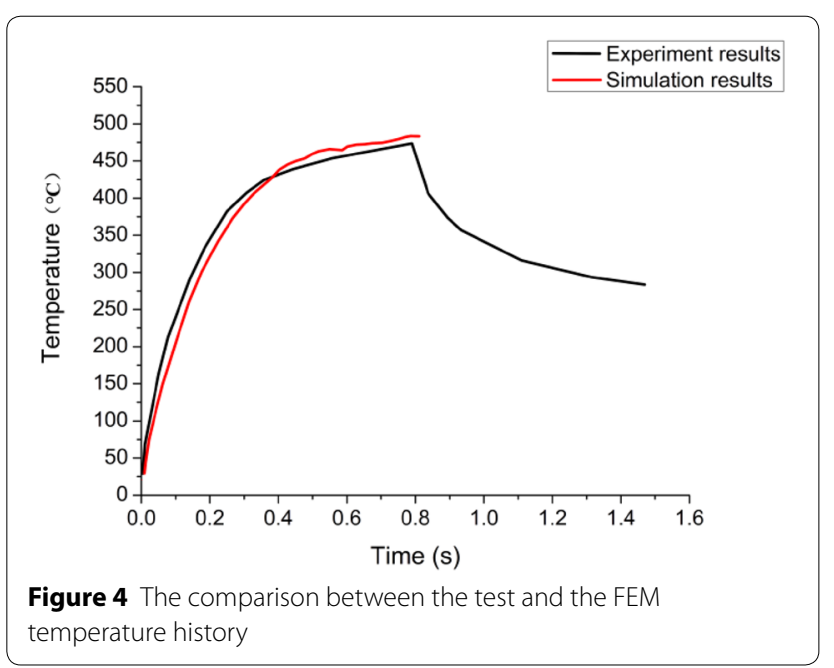




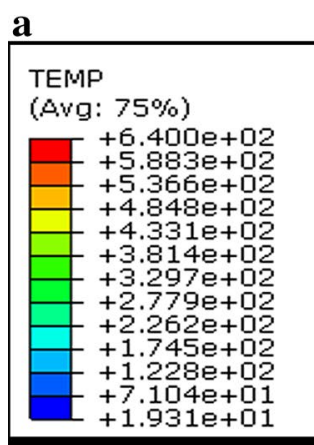

\section{Vibration}

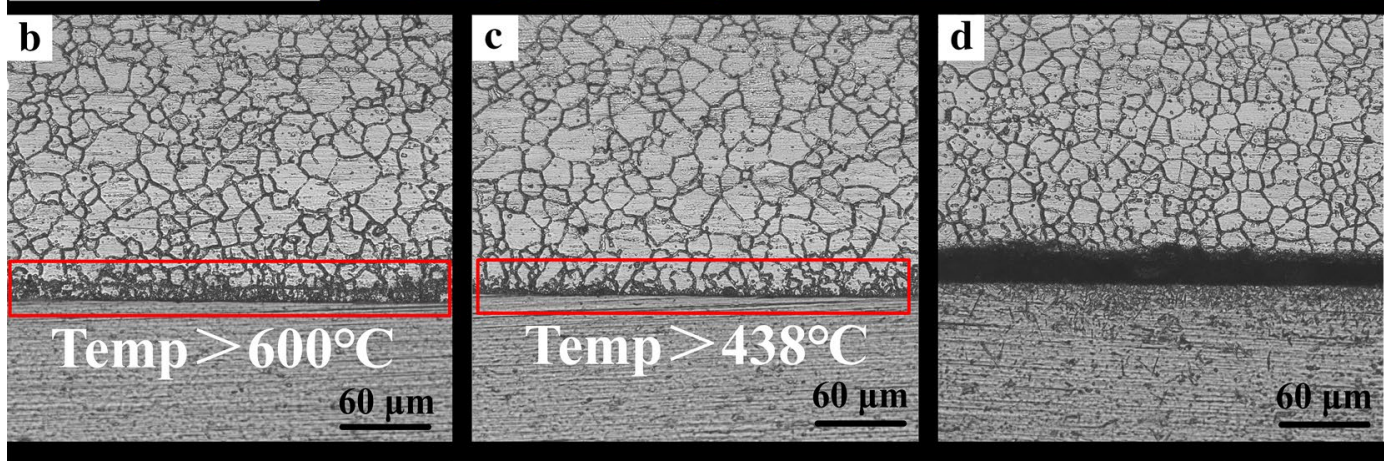

Figure 5 Cross-sectional morphology of the joint interface: $\mathbf{a}$ macro view; $\mathbf{b}$ the center of weld; $\mathbf{c}$ the edge of weld; $\mathbf{d}$ the non-welded zone

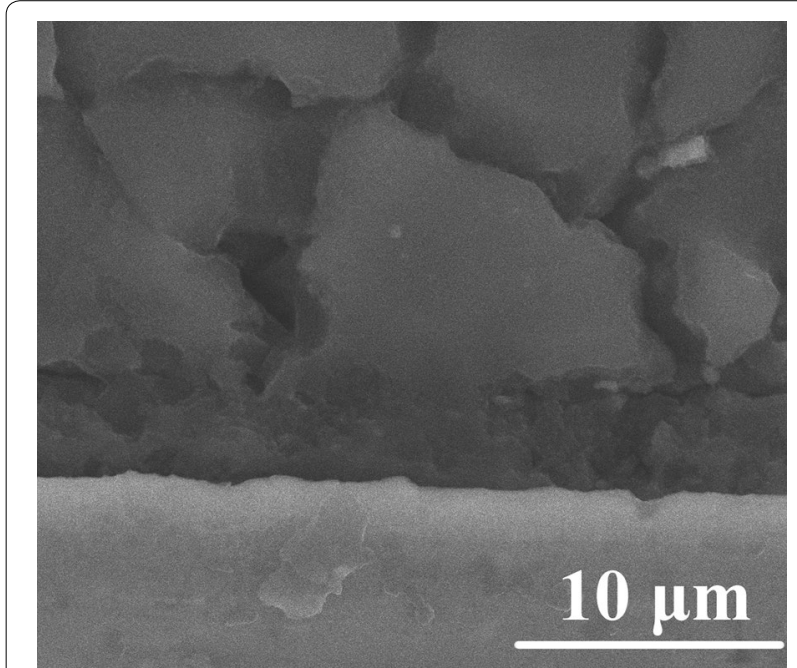

Figure 6 Morphology of the locally refined grains at the weld interface with 2000 times

of the local grain refinement at the solder joint interface is shown in Figure 6. From the figures, the grain size of the magnesium alloy at the interface is $3-4 \mu \mathrm{m}$, which is considerably finer compared with the average grain size of $30 \mu \mathrm{m}$ of the base material. Generally, grain refinement is induced by the liquid metal under rapid cooling conditions. Therefore, the local grain refinement layer at the interface indicate that the magnesium alloy at the interface is locally melted during magnesium-titanium heterogeneous metal welding; moreover, the temperature at that point exceeds $600{ }^{\circ} \mathrm{C}$, which reaches the melting temperature of the magnesium alloy. In the comparison with the cross-sectional view of the joint, the temperature at the center of the solder joint of numerical simulation also exceeds $600{ }^{\circ} \mathrm{C}$, which reaches the melting point temperature of the magnesium alloy; the edge temperature of the solder joint is $426-480{ }^{\circ} \mathrm{C}$; and the unwelded parts are highly consistent with the test, thereby further verifying the accuracy of numerical simulation results.

\subsection{Analysis of Temperature Field}

Figure $7(\mathrm{a})-(\mathrm{e})$ show the temperature field distribution along the $Y$-axis at the center of the solder joint at weld times of $0.05,0.1,0.2,0.4$, and $0.6 \mathrm{~s}$. The temperature field distribution indicates that temperature during welding is generated at the contact interface and is conducted to the surroundings. Figure 7(a) shows that in the initial welding stage, the temperature increase starts at the edge of the solder joint edge because of the initial deformation of the magnesium sheet under the vertical pressure, resulting in stress concentration at the edge of the solder joint. The contact at the edge is tight during vibration; thus, the temperature increase starts at the edge of the solder joint. With the progress of welding, heat spreads to the 

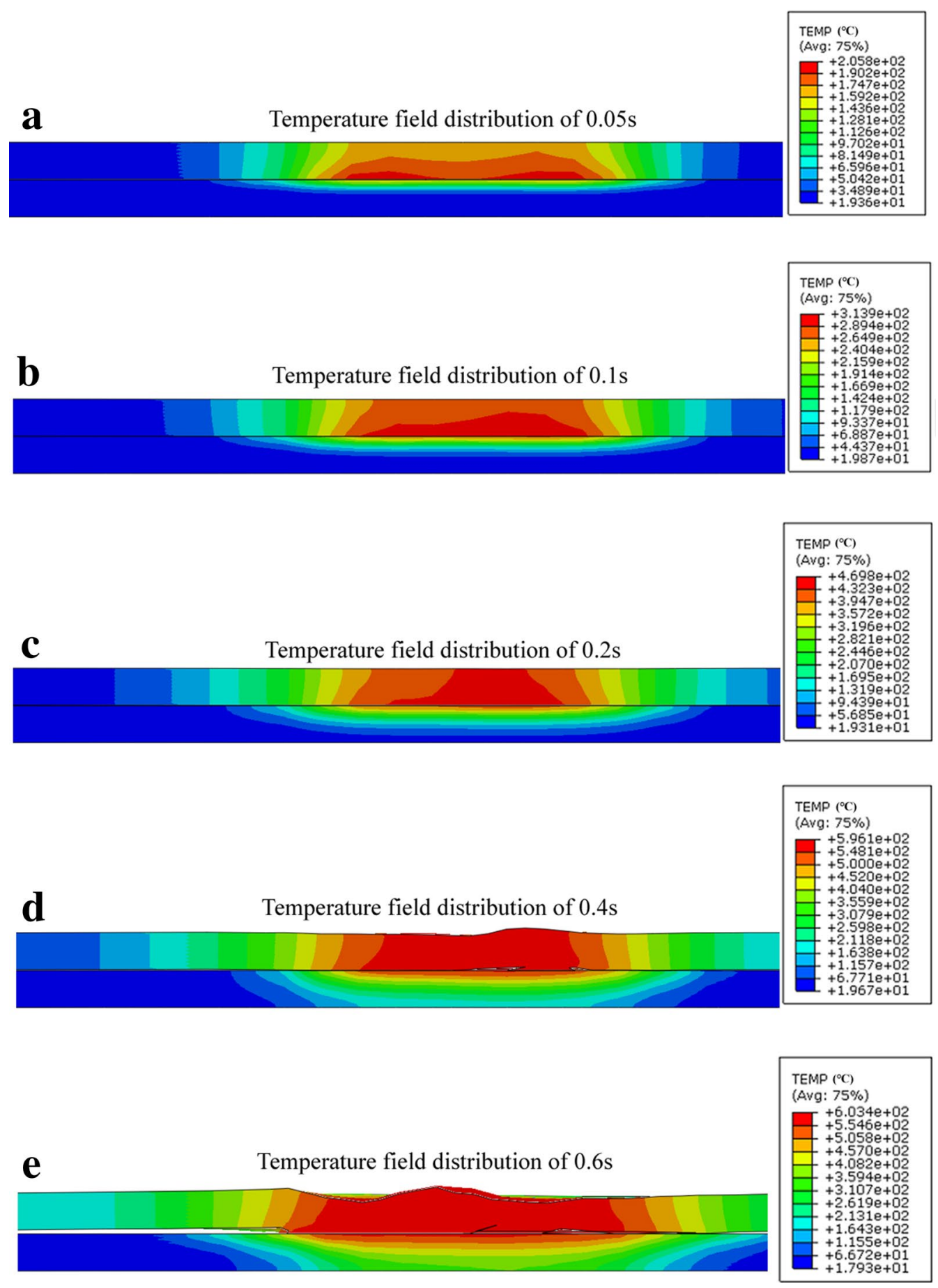

Figure 7 Temperature field distribution at different welding time points

surroundings, causing a large thermal-force deformation at the center of the solder joint. Therefore, the center position of the solder joint is increasingly tight, and the temperature increase starts from the center position interface to spread to the surroundings until the end of welding. Given that the thermal conductivity of the magnesium alloy is higher than that of the titanium alloy, the temperature increase at the magnesium alloy side is more rapid than that of the other alloy. When the welding time reaches $0.1 \mathrm{~s}$, the maximum temperature at the 
interface exceeds $289^{\circ} \mathrm{C}$; when the welding time reaches $0.2 \mathrm{~s}$, the maximum temperature at the interface exceeds $432{ }^{\circ} \mathrm{C}$; when the welding time reaches $0.4 \mathrm{~s}$, the maximum temperature at the interface exceeds $548{ }^{\circ} \mathrm{C}$ and approaches $600{ }^{\circ} \mathrm{C}$, and the temperature continues to pass to the surroundings; when the welding time reaches $0.6 \mathrm{~s}$, the maximum temperature at the interface exceeds $600{ }^{\circ} \mathrm{C}$. Notably, consistent with the test results, the maximum temperature growth rate decreases when the welding time exceeds $0.4 \mathrm{~s}$, whereas the range of solder joints increases at the maximum temperature. This phenomenon is attributed to the softening of magnesium alloy under the combined action of high temperature and ultrasonic energy, in addition to temperature conduction to the surroundings. Therefore, under vertical pressure, a tight bond exists at the solder joint and the range of solder joints at the maximum temperature is continuously expanded under the combined action of friction and plastic deformation heat.

\subsection{Analysis of Plastic Deformation}

Figure 8 shows a time history diagram of the plastic dissipative energy of the overall structure. When the material is plastically deformed, the energy is released in the form of heat, which is another source of ultrasonic welding temperature increase; thus, the level of dissipated energy represents the degree of plastic deformation. Figure 8 shows that in the first $0.35 \mathrm{~s}$, the entire welded structure is basically not plastically deformed due to its linear elastic state; hence, the heat in the first $0.35 \mathrm{~s}$ comes from the interface friction heat generation. After $0.35 \mathrm{~s}$, plastic dissipative energy is generated, representing the beginning of plastic deformation. As welding time increases, the slope of the plastic dissipative energy curve increases considerably, which indicates that plastic deformation rate increases, and the degree of plastic deformation of the overall structure begins to increase. This finding is due to the combination of temperature increase and ultrasonic softening effect; the material is softened, and plastic deformation easily occurs.

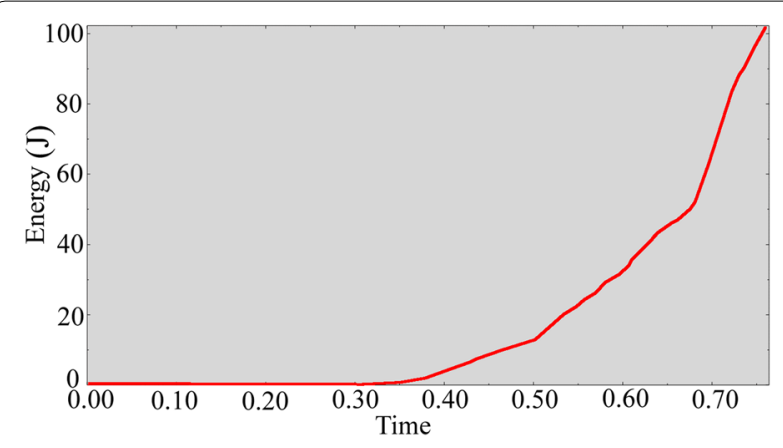

Figure 8 The plastic dissipation for whole model
Figure 9(a)-(d) show the plastic strain field distribution along the $Y$-axis at the center of the solder joint at weld times of $0.4,0.5,0.6$, and $0.7 \mathrm{~s}$. Figure 9 shows that the plastic deformation of the entire welded structure is mainly produced at the magnesium alloy. At $0.4 \mathrm{~s}$, certain plastic deformation occurs mainly at the center of the joint, with a small degree and extent of deformation; at $0.5 \mathrm{~s}$, the range and degree of plastic deformation at the interface considerably expand and diffuse to the top of the magnesium plate; at $0.6 \mathrm{~s}$, the range and degree of plastic deformation at the interface further increase. Upward warpage visible to the naked eye occurs at the edge of the magnesium plate because of the deformation of the overall solder joint structure, which is due to long welding time under the synergistic effect of the vertical pressure and the ultrasonic frequency vibration. This deformation may crucially affect joint fatigue performance [34] and influences the interface failure form of the joint tensile strength test [35]; at $0.7 \mathrm{~s}$, the range and degree of plastic deformation at the interface further expand, warping deformation of the edge of the welded structure becomes increasingly evident, and the plastic flow of the material at the joint tends to occur to both sides under the extrusion of vertical pressure. Therefore, the overall trend of plastic deformation occurs at the center of the solder joint and spreads to both sides and the top as soldering time increases.

\section{Conclusions}

In this study, magnesium-titanium ultrasonic welding test is conducted, and the thermo-mechanical analyses of magnesium-titanium ultrasonic welding is performed using FEM. The following conclusions are obtained.

During welding, the first $0.4 \mathrm{~s}$ mainly involves the temperature increase phase. At this stage, the temperature increases rapidly in a linear trend. After $0.4 \mathrm{~s}$, the magnesium alloy is softened by the combination of high temperature and ultrasonic softening, which makes the temperature rise insignificant. The microscopic analysis indicates that at the welding time of $0.5 \mathrm{~s}$, the magnesium alloy in the center of the solder joint is partially melted and generates the liquid phase.

The friction coefficient of the magnesium-titanium ultrasonic welding interface can be considered as an average constant value of 0.28 . The maximum temperature at the interface can exceed $600{ }^{\circ} \mathrm{C}$ to reach the melting point temperature of the magnesium alloy. There is no plastic deformation before $0.35 \mathrm{~s}$. Then, plastic deformation begins after $0.35 \mathrm{~s}$ and occurs at the magnesium side at the center of the interface. As the welding time continues to increase, the range of plastic 


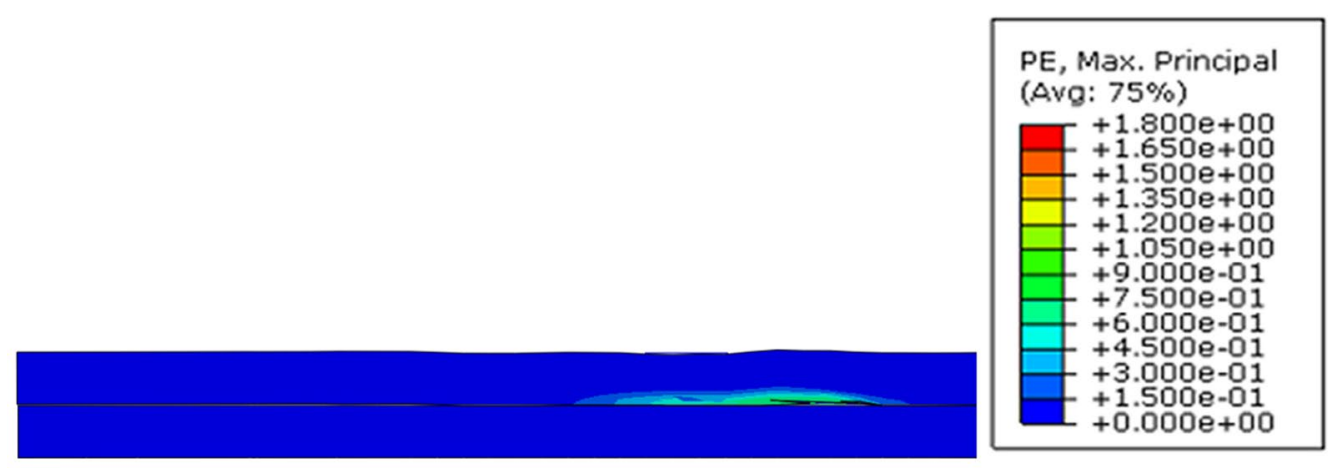

b The plastic deformation distribution of $0.5 \mathrm{~s}$

c The plastic deformation distribution of $0.6 \mathrm{~s}$

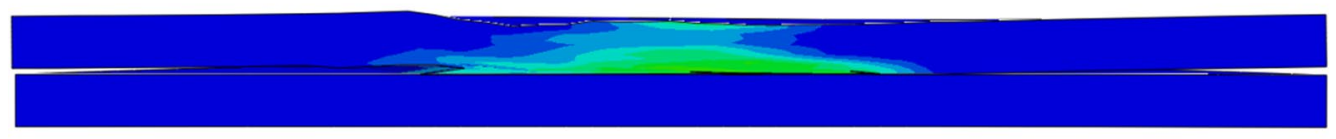

d The plastic deformation distribution of $0.7 \mathrm{~s}$

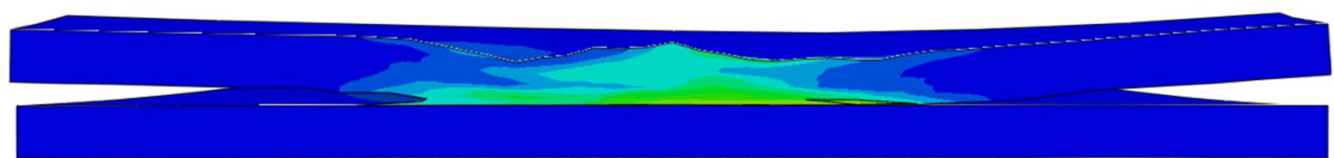

Figure 9 The plastic strain field distribution along the $Y$-axis at the center of the solder joint

deformation and the degree of deformation increase considerably, extending to both sides and the top of the magnesium plate.

\section{Authors' Contributions}

DZ and KZ were in charge of the whole trial; DZ and DR wrote the manuscript; PS assisted with experimentation; XG assisted with FEM. All authors read and approved the final manuscript.

\section{Authors' Information}

Dewang Zhao, born in 1986, is currently a Postdoctoral at School of Materials Science and Engineering, Dalian University of Technology, China. His research interests include advanced manufacturing and welding. Tel: +8618545051095; E-mail: dewangzhao@qq.com.

Daxin Ren, born in 1982, is currently a lecturer at Dalian University of Technology, China. His research interests include advanced manufacturing and welding.

Kunmin Zhao, born in 1971, is currently a professor at State Key Laboratory of Structural Analysis for Industrial Equipment, Dalian University of Technology, China. "The one-thousand-talents scheme" specially invited Expert. His research interests include advanced manufacturing and metal forming process.

Pan Sun, born in 1987, is currently an engineer at Shanghai Ship yard, China.

Xinglin Guo, born in 1956, is currently a professor at State Key Laboratory of Structural Analysis for Industrial Equipment, Dalian University of Technology, China. His research interests include structural vibration and fatigue. 
Liming Liu, born in 1967, is currently a professor at School of Materials Science and Engineering, Dalian University of Technology, China. His research interests include welding technology and equipment.

\section{Acknowledgements}

The authors sincerely thanks to Professor Li-Ming Liu of Dalian University of Technology for his critical discussion and reading during manuscript preparation.

\section{Competing Interests}

The authors declare that they have no competing interests.

\section{Funding}

Supported by National Natural Science Foundation of China (Grant Nos. U1764251, 51775160), and Fundamental Research Funds for the Central Universities of China (Grant No. DUT19LAB24).

\section{Author Details}

${ }^{1}$ School of Materials Science and Engineering, Dalian University of Technology, Dalian 116024, China. ${ }^{2}$ School of Automotive Engineering, Dalian University of Technology, Dalian 116024, China. ${ }^{3}$ Institute of Industrial and Equipment Technology, Hefei University of Technology, Hefei 230601, China. ${ }^{4}$ Shanghai Shipyard Co., Ltd., Shanghai 200000, China. ${ }^{5}$ Department of Engineering Mechanics, State Key Laboratory of Structural Analysis for Industrial Equipment, Dalian University of Technology, Dalian 116024, China.

Received: 31 August 2018 Revised: 30 May 2019 Accepted: 8 November 2019

Published online: 29 November 2019

\section{References}

[1] H Li, H Choi, C Ma, et al. Transient temperature and heat flux measurement in ultrasonic joining of battery tabs using thin-film microsensors. Journal of Manufacturing Science and Engineering, 2013, 135(5): 051015.

[2] $L X i, M$ Banu, S Jack Hu, et al. Performance prediction for ultrasonically welded dissimilar materials joints. Journal of Manufacturing Science and Engineering, 2017, 139(1): 011008.

[3] S Shawn Lee, THyung Kim, S Jack Hu, et al. Analysis of weld formation in multilayer ultrasonic metal welding using high-speed images. Journal of Manufacturing Science and Engineering, 2015, 137(3): 031016.

[4] D Lee, E Kannatey-Asibu, W Cai. Ultrasonic welding simulations for multiple layers of lithium-ion battery tabs. Journal of Manufacturing Science and Engineering, 2013, 135(6): 061011.

[5] H S Shin, M de Leon. Parametric study in similar ultrasonic spot welding of A5052-H32 alloy sheets. Journal of Materials Processing Technology, 2015, 224: 222-232.

[6] F Haddadi, F Abu-Farha. The effect of interface reaction on vibration evolution and performance of aluminium to steel high power ultrasonic spot joints. Materials \& Design, 2016, 89: 50-57.

[7] V K Patel, S D Bhole, D L Chen. Ultrasonic spot welded AZ31 magnesium alloy: Microstructure, texture, and lap shear strength. Materials Science and Engineering: $A, 2013,569: 78-85$

[8] V K Patel, S D Bhole, D L Chen. Ultrasonic spot welding of aluminum to high-strength low-alloy steel: microstructure, tensile and fatigue properties. Metallurgical and Materials Transactions A, 2014, 45(4): 2055-2066.

[9] V K Patel, S D Bhole, D L Chen, et al. Solid-state ultrasonic spot welding of SiCp/2009Al composite sheets. Materials \& Design, 2015, 65: 489-495.

[10] A Panteli, J D Robson, I Brough, et al. The effect of high strain rate deformation on intermetallic reaction during ultrasonic welding aluminium to magnesium. Materials Science and Engineering: A, 2012, 556: 31-42.

[11] M Shakil, N H Tariq, M Ahmad, et al. Effect of ultrasonic welding parameters on microstructure and mechanical properties of dissimilar joints. Materials \& Design, 2014, 55: 263-273.

[12] DW Zhao, K M Zhao, DX Ren, et al. Ultrasonic welding of MagnesiumTitanium dissimilar metals: A study on influences of welding parameters on mechanical property by experimentation and artificial neural network. Journal of Manufacturing Science and Engineering, 2017, 139(3): 031019.
[13] Z L Ni, H J Zhao, P B Mi, et al. Microstructure and mechanical performances of ultrasonic spot welded Al/Cu joints with Al 2219 alloy particle interlayer. Materials \& Design, 2016, 92: 779-786.

[14] M P Satpathy, A Kumar, S K Sahoo. Effect of brass interlayer sheet on microstructure and joint performance of ultrasonic spot-welded coppersteel joints. Journal of Materials Engineering and Performance, 2017, 26(7): 3254-3262.

[15] M P Satpathy, S K Sahoo. Mechanical performance and metallurgical characterization of ultrasonically welded dissimilar joints. Journal of Manufacturing Processes, 2017, 25: 443-451.

[16] DX Ren, K M Zhao, M Pan, et al. Ultrasonic spot welding of magnesium alloy to titanium alloy. Scripta Materialia, 2017, 126: 58-62.

[17] F A Mirza, M A acWan, S D Bhole, et al. Effect of welding energy on microstructure and strength of ultrasonic spot welded dissimilar joints of aluminum to steel sheets. Materials Science and Engineering: A, 2016, 668: 73-85.

[18] K K Chen, Y S Zhang. Mechanical analysis of ultrasonic welding considering knurl pattern of sonotrode tip. Materials \& Design, 2015, 87: 393-404.

[19] C Zhang, L J Li. A coupled thermal-mechanical analysis of ultrasonic bonding mechanism. Metallurgical and Materials Transactions B, 2009, 40(2): 196-207.

[20] KK Chen, Y S Zhang, H Z Wang. Effect of acoustic softening on the thermalmechanical process of ultrasonic welding. Ultrasonics, 2017, 75: 9-21.

[21] D Lee, E Kannatey-Asibu, W Cai. Ultrasonic welding simulations of multiple, thin and dissimilar metals for battery joining. Dynamic Systems and Control Division. ASME/ISCIE 2012 International Symposium on Flexible Automation, June 18-20, 2012, St. Louis, Missouri, USA, 2012: 573-584.

[22] W Kim, A Argento, A Grima, et al. Thermo-mechanical analysis of frictional heating in ultrasonic spot welding of aluminium plates. Proceedings of the Institution of Mechanical Engineers, Part B: Journal of Engineering Manufacture, 2011, 225(7): 1093-1103.

[23] E de Vires. Mechanics and mechanism of ultrasonic metal welding. The Ohio State University, 2004

[24] S Elangovan, S Semeer, K Prakasan. Temperature and stress distribution in ultrasonic metal welding: An FEA-based study. Journal of Materials Processing Technology, 2009, 209(3): 1143-1150.

[25] D Umbrello. Finite element simulation of conventional and high speed machining of Ti6Al4V alloy. Journal of Materials Processing Technology, 2008, 196(1-3): 79-87.

[26] Chenyang Xie, Zhengqiang Zhu, Xiaolong Wang. Numerical simulation on temperature and stress field in ultrasonic welding process for titanium alloy. Hot Working Technology, 2013, 42: 140-147.

[27] F Feng, S Y Huang, Z H Meng, et al. A constitutive and fracture model for AZ31B magnesium alloy in the tensile state. Materials Science and Engineering: A, 2014, 594: 334-343.

[28] Dong Jia, Jun Mo, Xicheng Huang, et al. On the fracture behavior of magnesium alloy MB2 subjected to high stress triaxiality stretching. Journal of Experimental Mechanics, 2016, 31 (1): 87-95. (in Chinese)

[29] Dong Jia, Xicheng Huang, et al. Fracture behavior of magnesium alloy MB2 under quasi-static and dynamic tension loading based on JohnsonCook model. Explosion and Shock Waves, 2017, 37: 1010-1016. (in Chinese)

[30] G R Johnson, W H Cook. Fracture characteristics of three metals subjected to various strains, strain rates, temperatures and pressures. Engineering Fracture Mechanics, 1985, 21(1): 31-48.

[31] A Siddiq, E Ghassemieh. Thermomechanical analyses of ultrasonic welding process using thermal and acoustic softening effects. Mechanics of Materials, 2008, 40(12): 982-1000.

[32] Y Gao, C Doumanidis. Mechanical analysis of ultrasonic bonding for rapid prototyping. Journal of Manufacturing Science and Engineering, 2002, 124(2): 426

[33] Z H Huang, M Lucas, M J Adams. Influence of ultrasonics on upsetting of a model paste. Ultrasonics, 2002, 40(1-8): 43-48.

[34] DW Zhao. Effect of welding parameters on tensile and fatigue properties of ultrasonic spot welded dissimilar joints of magnesium to titanium sheets. Journal of Mechanical Engineering, 2017, 53(24): 118. (in Chinese)

[35] D W Zhao, DX Ren, K M Zhao, et al. Effect of welding parameters on tensile strength of ultrasonic spot welded joints of aluminum to steel - By experimentation and artificial neural network. Journal of Manufacturing Processes, 2017, 30: 63-74. 